\title{
AKULAH ROTI HIDUP \\ Analisis Homili ke-44 sampai dengan ke-47 \\ Yohanes Krisostomus atas Injil Yohanes
}

Antonius Baur Asmoro

\begin{abstract}
:
The bread of lifeis the special theme in the Gospel of John. Even, among the Gospels, it is only the Gospel of John that gives this theme. Nowadays, there are many questions about the meaning of bread of life. Many scholars said that the bread of life has a connection with the eucharist. But, is there only one meaning of the bread of life? John Chrysostom dedicated his $44^{\text {th }}$ homily to the $47^{\text {th }}$ homily as the homily which tells about the bread of life. John Chrysostom offered another interpretation of the bread of life. For him, the bread of life tells about the Jesus himself facing the teaching of Arius (Arianism) that spreads in his service territory. The bread of life becomes an apology of the Nicean faith facing the Arianism. The emphasis is that the bread of life is the Son itself who has same nature (homo-ousios) with the Father. The faith of the Son guides all mankind to the ressurection and the everlasting life.
\end{abstract}

\section{Kata-KataKunci:}

Roti, roti hidup, bekerja, tanda, misteri, percaya, Kristus, hidup kekal, dan Arianisme.

\section{PENDAHULUAN}

Injil Yohanes bab VI menampilkan pembicaraan mengenai Roti Hidup. Teks ini terasa begitu unik, secara literertidak begitu mudah dipahami, danmemiliki nuansa spiritual yang khas. ${ }^{1} \mathrm{R}$. Schnackenburg mengatakan, teks Roti Hidup ini menegaskan gagasan mengenai ekaristi. ${ }^{2}$ St. Yustinus Martir (100-165) yang dikenal sebagai penafsir awal Injil Yohanes pun membaca teks Yoh 4ini sebagai teks yang berbicara mengenai Ekaristi. ${ }^{3}$ Yohanes Krisostomus ${ }^{4}$ yang dikenal dengan gelar Si Mulut Emasmembahas tema ini dalam empat (4) buah homili eksegetis ${ }^{5}$ mengenai Yoh 4, yang berjumlah 6 homili. ${ }^{6}$ Quasten mengatakan bahwa homili tersebut ditulis dalam rangka melawan ajaranArianisme yang mengatakanbahwa Putera tidak sehakikat dengan Bapa dan Putera diciptakan oleh Bapa. ${ }^{7}$
Pandangan J. Quasten tersebut menantang penulis untuk mendalami lebih lanjut pemikiran Yohanes Krisostomus mengenai Roti Hidup. Penulis merumuskan hipotesis sebagaiberikut: Menurut Yohanes Krisostomus, dalam Homili ke 44 samapai ke 47 tentang Injil Yohanes,Roti Hidup tidak pertama-tama mengacu pada pemahaman tentang Ekaristi, tetapi menegaskan identitas Yesus sebagai sebuah apologi iman berhadapan dengan Arianisme. Homili-homili atas tema Roti Hidup ini yang dibangun oleh Yohanes Krisostomus merupakan sebuah apologi iman Konsili Nicea (325) tentang Putera yang sehakikat dengan Bapa berhadapan dengan Arianisme.

Untuk membuktian hipotesis ini, pertamatama penulis akan memberikan ulasan dan analisis tentang keempat homili yang merujuk pada dua sumber utama teks, yakni homili eksegetis tentang Roti Hidup dalam teks Bahasa Inggris yang 
diterjemahkan oleh Philip Schaff ${ }^{8}$ dan juga teks asli berbahasa Yunani ${ }^{9}$.Kemudian homili tersebut dilihat dalam terang apologia atas Arianisme.

\section{HOMILI TENTANG ROTI HIDUP}

Keempat homili Yohanes Krisostomus iniakan dilihat sebagai sebuah kesatuan sekaligus dilihat secara parsial. Dalam homili ke-44, Yohanes memulai ulasannya dengan mengutip ayat 26-27. Yohanes Krisostomus mengantar para pendengarnya masuk dalam sebuah misteri agung, Tuhan Yesus Kristus, dengan berpangkal darisebuah pengalaman dasar manusia yakni penga-laman makan,pada peristiwa penggandaan roti (Yoh 6:1-12). Yohanes Krisostomus menunjukkan ketakjuban para murid dan orangorang yang mengikuti-Nya atas peristiwa penggandaan roti yang dilakukan dan mereka kenyang. Ketakjuban ini berhenti pada sebuah pengalaman duniawi belaka, pengalaman lapar dan kenyang. Hal ini serupa dengan yang digambarkan dalam Perjan-jian Lama ketika nenek moyang umat Israel menerima manna di padang gurun.

Dalam homili ke 44 ini, Yohanes Krisostomus meminta para pendengarnya untuk masuk dalam sebuah misteri makanan yang dapat bertahan sampai kepada hidup kekal. Ia mengantar para pendengarnya untuk masuk lebih dalam dari sekedar pengalaman fisik. Masuk dalam pengalaman rohani itu tidak mengabaikan tindakan manusia bekerja. Hanya saja, tindakan bekerja manusia itu diarahkan untuk mendapatkan makanan yang bertahan sampai kepada hidup yang kekal. Di sini, yang ditonjolkan adalah bahwa apa yang diupayakan oleh manusia dalam bekerja itu tak semata hal-hal duniawi, tetapi diarahkan pada hal-hal rohani yang kekal sifatnya. Bisa dikatakan bahwa homili ke-44 ini menjadi sebuah cara pikir yang dibangun oleh Yohanes Krisostomus untuk mengantar para pendengarnya masuk dalam misteri Roti Hidup.

Dalam homili ke-45, Yohanes Krisostomus menjelaskan bahwa ketidakmampuan para pendengar Yesus memahami perkataan-Nya tentang Roti Hidup itu adalah karena kerakusan yang ada dalam diri mereka. Mereka berhenti pada tanda sebagai tanda karena kerakusan mereka itu mengantar mereka ketidakmengertian $\left(\dot{\alpha} \sigma \theta^{\prime} \in \in \in L \alpha\right)$. Mereka tidak memahami apa yang Yesus maksudkan dengan Roti yang mengacu pada Diri-Nya sendiri. Di sinilah, Yesus mulai berbicara tentang misteri. Yohanes Kristostomus menegaskan bahwa untuk masuk dalam misteri yang Yesus nyatakan, perlu sikap percaya, yang berarti memasrahkan segala ketidak-tahuan pada Allah dan menaruh kepercayaan pada-Nya agar dapat masuk dalam misteri Yesus itu sendiri sehingga dapat diselamatkan.

Tekanan di homili ke-45 ini adalah bahwa keselamatan itu datang dari dan dalam Diri Yesus. Rumusan "Ego eimi" menegaskan bahwa Yesus itu bukanlah pribadi baru yang datang, tetapi perwahyuan yang telah dinyatakan oleh Allah sendiri. Di sini, Yohanes Krisostomus menegaskan identitas Yesus adalah sebagai roti hidup. Namun, penegasan identitas ini masih tertunda sifatnya. Dalam homili ke-46 dan ke-47, penegasan ini akan semakin diperterang, danakan tampak jelas bahwa Roti Hidup ini memiliki keutuhan makna dalam keterkaitan dengan keselamatan dan kehidupan kekal yang ditawarkan oleh Yesus.

Dalam homili ke-46, Yohanes Krisostomus masih menunda penjelasan tentang Roti Hidup dengan membahas sikap para pendengar Yesus yang bersungut-sungut. Ketidak-mengertian para pendengar Yesus itu, menurut Yohanes Krisostomus, tidak bermuara pada sikap murid sejati. Para pendengar Yesus tetapbertahan pada cara pikir duniawi. Ketidakmengertian ini semakin menjadi-jadi ketika Yesus mulai berbicara tentang menyantap daging dan meminum darah-Nya demi sebuah keselamatan. Menurut Yohanes Krisostomus, Yesus mengantar para pendengar-Nya pada sebuah misteri akan diri-Nya dalam perjamuan kudus. Daging dan darah-Nya menjadi kurban keselamatan bagi semua manusia yang percaya pada-Nya. Keselamatan itu ditandai dengan adanya kebangkitan. Dan, kebangkitan pada hidup kekal itu tidak dialami oleh mereka yang tidak percaya dan tidak menyantap daging dan darah-Nya. Di sini, tampak adanya sebuah suasana tentang ekaristi yang dibangun oleh Yohanes Krisostomus.

Dalam Homili ke-47, Yohanes Krisostomus berbicara tentang pokok ajaran dari ulasan tentang Roti Hidup, yakni tentang hidup kekal. Ajaran ini harus dipahami dalam rangka ekonomi keselamatan yang Allah tawarkan kepada manusia.Hidup kekal menjadi kenyataan di mana tidak ada lagi kematian dan manusia menikmati hidup tanpa akhir dalam kebersamaan dengan-Nya dalam kasih-Nya. Hidup kekal itu dianugerahkan itu dijanjikan kepada mereka yang percaya dan menyantap daging dan darah-Nya. Yang menarik dalam homili ini adalah munculnya beberapa gelar Yesus secara bersamaan, yaitu Anak Manusia, Anak Allah, dan Kristus. 
Munculnya gelar-gelar Yesus di sini harus dilihat sebagai sebuah penegasan akan identitas Yesus yang dikemas dengan begitu indah dalam beragam ajakan pesan moral dan spiritual bagi para jemaatnya. Jika semata berpijak pada cara pandang manusiawi belaka,orang akan jatuh pada kesalahan yang dibuat oleh para pendengar Yesus yang menolak tawaran keselamatan-Nya. Keterbukaan pada hal-hal spiritual atau rohani mengantar pada pemahaman akan identitas Yesus yang sungguh-sungguh Allah dan sehakikat dengan-Nya. Di sini nampaklah bahwa homilihomilinya ini menjadi sebuah apologia atas ajaran iman Konsili Nikea yang menegaskan kesehakikatan Anak dengan Bapa. Dalam keempat homilinya Yohanes Krisostomus secara implisit dan eksplisit menegaskan sikapnya atas penegasan identitas Yesus, Sang Anak yang sehakikat dengan Bapa.

\section{AKULAH ROTI HIDUP: APOLOGIA MELAWAN ARIANISME}

\subsection{Makna Roti}

Berhadapan dengan pengaruh Arianisme,melalui keempat homili atas Roti Hidup, Yohanes Krisostomus memberikan sebuah penegasan iman akan Yesus Kristus dengan berangkat dari kata roti. Kata roti inilah yang menjadi pintu masuk sekaligus pusat penjelasan darinya untuk menegaskan pribadi Yesus Krisus sendiri. Dalam homili ke 44-47, kata roti itu muncul sebanyak 53 kali. ${ }^{10}$ Tentu kata ini menjadi kata kunci utama dalam ulasan tema roti hidup. Menarik bahwasanya secara kuantitatif, kata ini muncul secara berbeda-beda dalam tiap homili, sebanyak lima (5) kali dalam homili ke-44, 26 kali dalam homili ke-45, 18 kali dalam homili ke-46, dan empat (4) kali dalam homili ke-47. Bila dicermati ada semacam pola penjelasan yang berpuncak pada homili ke-45 yang mengulas ayat 28-40 dan homili ke-46 yang mengulas ayat 4152. Homili ke-44 menjadi pengantar masuk dalam penjelasan dan homili ke-47 menjadi semacam penutup penjelasan. Pola ini nampak dalam diagram berikut:

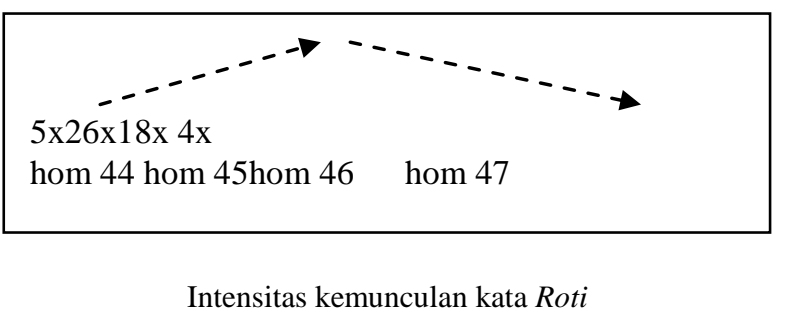

Kata roti dalam tiap homili Yohanes Krisostomus bersanding dengan beberapa kata kunci lainnya. Kata-kata lain itu membantu menjelaskan makna kata roti dalam rangkaian pemahaman tentang pribadi Yesus sendiri. Dan, dalam sebuah pola, penulis menggambarkannya sebagai berikut:

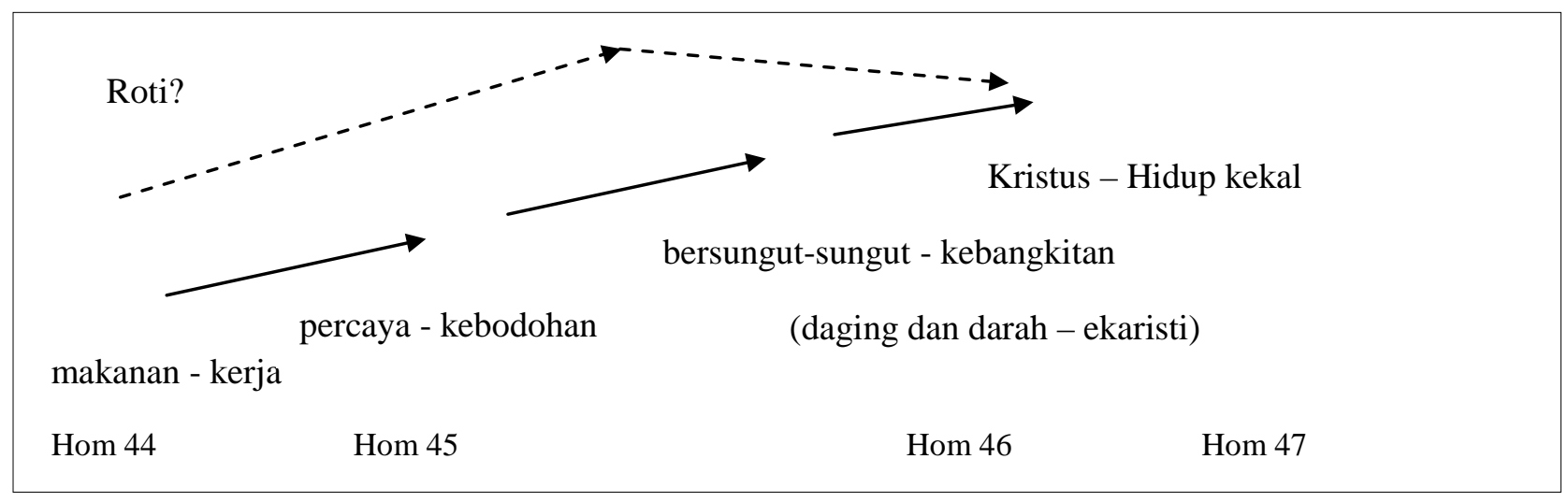

Kata Roti dalam perjumpaan dengan kata kunci lain

Dalam homili ke-44, kata roti muncul bersama dengan kata bekerja. Dalam homili ke45, kata roti ini muncul seiring dengan disposisi dasar para pendengar Yesus, yakni sikap percaya. Namun, di dalamnya ada tegangan antara sikap percaya dan kebodohan dalam diri para pendengar Yesus. Dalam homili ke-46, kata roti dijelaskan dengan kata bersungut-sungut dan kebangkitan. Ini menjadi sebuah kelanjutan dari katakebodoh- an yang muncul dalam homili ke-45. Kebodohan ini mengakibatkan sikap bersungut-sungut dan sulit masuk dalam misteri roti itu sendiri yang mengantar pada kebangkitan. Yang percaya akan mengalami kebangkitan. Dalam homili ke-47, tekanannya semakin memuncak, yakni bahwa roti itu tidak lagi ditonjolkan, tetapi Kristus sendiri yang semakin ditampilkan. Tak hanya Kristus, tetapi juga gagasan hidup kekal. 
Tampak jelas bahwa dari kedua pola ini intensitas kemunculan kata roti yang menurun di homili ke-47. Roti itu bukanlah lagi yang menjadi fokus utama, tetapi Kristus-lah yang menjadi utama. Kristus menjadi pribadi yang membawa manusia yang menyantap-Nya kepada hidup kekal. Dalam penjelasan pola ini, memang tampak sekali suasana tegangan manusiawi sebagai sebuah proses dalam diri manusia. Tetapi, inilah yang menjadi khas dalam ulasan Yohanes Krisostomus, bahwasanya tegangan manusiawi ini turut mendapat perhatian untuk masuk dalam misteri ilahi itu sendiri.

Dari kedua gambaran pola yang coba penulis buat ini, tampak bahwa ada sebuah metode pewartaan yang ingin disampaikan oleh Yohanes Krisostomus. Dari dua pola yang muncul tampak, ada sebuah puncak dari intensitas kemunculan dari kata roti itu sendiri. Namun, intensitas itu tidak pertama-tama menjadi tanda tentang sebuah penjelasan apa arti kata roti, tetapi menjadi sebuah tahap klimaks masuk dalam misteri roti. Penjelasan kata roti itu malah berpuncak pada homili ke47 atau bagian akhir dari seluruh ulasan. Penjelasan kata roti itu bermuara pada pribadi Kristus sendiri.

\subsubsection{PemahamanRotiBerangkat dari Pengalaman Dasariah}

Dalam homili ke-44, Yohanes Krisostomus mengantar para pendengarnya untuk masuk dalam misteri roti dengan berangkat dari pengalaman dasar manusia, yakni makan dan bekerja. Dua kata ini sangat dominan muncul sepanjang homili ke44. Sangat logis bahwa agar bisa mendapatkan roti untuk makan itu, seseorang itu harus bekerja. Yohanes Krisostomus memulai gagasan teologisnya dengan berangkat dari pengalaman konkret sehari-hari. Di sinilah tampak sekali apa yang dinyatakan oleh Paus Pius XII, dalam Divino Afflante Spiritu, bahwa Yohanes Krisostomus menekankan metode penafsiran"synkatábasis". Paus Pius XII memahami,metode penafsiran ini merupakan metode yang menjelaskan bahwa sabda-sabda Ilahi itu yang tergambarkan dan terekspresikan dalam kata-kata manusia itu serupa dengan bahasa manusia dalam banyak cara. ${ }^{11}$ Maksudnya, sabda-sabda Ilahi itu bisa dikenali oleh manusia dengan bahasa manusia. Dengan metode penafsiran ini, Yohanes Krisostomus mencoba untuk membahasakan sabda-sabda Ilahi itu dalam bahasa manusia sesuai konteks jemaatnya.Ia menggunakan bahasa yang sederhana dan menarik untuk menjelaskan makna kata roti. Dalam menarik korelasi dengan Perjanjian
Lamapengalaman bangsa Israel akan manna di padang gurunYohanes Krisostomus mengantar masuk dalam sebuah refleksi dalam tataran spiritual atau rohani. Roti yang dimaksudkan oleh Yesus itu tak bisa dimengerti jika hanya menggunakan cara pikir manusiawi belaka, karena seseorang bisa jatuh pada pencapaian sebuah kehormatan belaka dari apa yang dia lakukan. Roti yang bisa mengenyangkan banyak orang menumbuhkan kekaguman dan rasa hormat dari mereka yang menikmatinya.

Akan tetapi, yang dimaksudkan Yohanes Krisostomus adalah bahwa roti itu merupakan sesuatu yang dirindukan oleh seseorang dan diupayakan dengan bekerja keras. Roti itu bukanlah makanan yang dapat binasa, tetapi roti yang dimaksud adalah roti yang yang bertahan sampai hidup kekal. Apakah itu? Misteri itu dijawab dalam homili berikutnya. Yang penting di sini adalah kerinduan untuk menyantap roti itu. Gambaran itu secara implisit dinyatakan demikian oleh Yohanes Krisostomus,

Maka, marilah kita tidak melekatkan diri pada hal-hal yang dengan cepat berubah, menghilang, dan menyimpang. Tetapi, marilah kita melekatkan diri pada hal-hal yang kekal dan tak tergoyahkan. (Hom 44.2.VI)

\subsubsection{Membangun Disposisi Batin untuk Memahami Roti}

Dalam homili ke-45, kerinduan untuk menyantap Roti itu semakin meningkat. Namun, Roti itu tetap tidak dimengerti. Yohanes Krisostomus menggambarkan kisah eksodus dalam Perjanjian Lama sebagai sebuah cara untuk memahami bahasa dalam Yoh 4. Menurut Susan Hylen, di sini, tersirat makna bahwa Yohanes Krisostomus menunjukkan eratnya keterkaitan antara Perjanjian Lama dan Perjanjian Baru. Yohanes Krisostomus berpegang bahwa "makna yang lebih luhur" (theoria) dari sebuah teks harus dihubungkan dengan makna historisnya (historia). Peristiwa-peristiwa Perjanjian Lama dilihat sebagai sesuatu yang historis dan sangat penting karena peristiwa-peristiwa itu terarah pada keselamatan dalam Kristus. ${ }^{12}$

Dan ia menyebut hal itu "roti sejati” ( $\propto \rho \rho \tau \nu \nu$

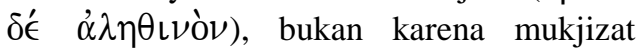
manna yang keliru, tetapi karena manna itu

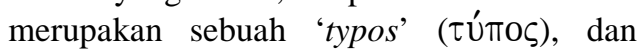
bukan kebenaran sejati (Hom 45.1.IX).

Kutipan ini menjadi begitu menarik untuk menjawab pertanyaan apakah yang dimaksud oleh 
Yesus tentang manna itu sendiri? Menurut Hylen, Yohanes Krisostomus di sini menggambarkan sebuah kesejajaran dari dua buah peristiwa tetapi mengindikasikan sebuah perbedaan sebaik mungkin. Yohanes Krisostomus menerapkan metode tipologi, ${ }^{13}$ manna sebagai sebuah 'typos' Kristus. Dalam pendekatan ini, tampak jelas bahwa Kristus menegaskan makanan rohani "dalam rangka menunjukkan bahwa semua yang

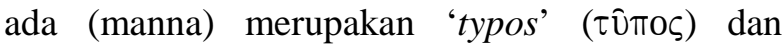
bayangan ( $\sigma \kappa i \alpha)$, sementara realitas itu hadir secara nyata dan jauh lebih luhur dari pada manna karena dampaknya sendiri, yakni kebangkitan (Hom 46.2.XXI-XXII) ${ }^{14}$ Kisah manna itu menjadi sebuah persiapan akan makanan rohani yang diberikan oleh Kristus.

Dari cara berpikir ini, Yohanes Krisostomus menegaskan bahwa para pendengar Yesus tidak sampai pada pemahaman seperti apa yang Ia

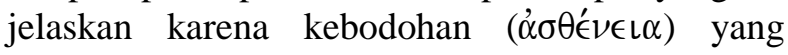
mereka ciptakan sendiri dengan menaruh hati pertama-tama pada kerakusan ( $\left.\gamma \alpha \sigma \tau \rho \iota \mu \alpha \rho \gamma^{\prime} \alpha\right)$ akan hal-hal duniawi. Ketika mereka tidak sampai pada pemahaman bahwa Roti itu adalah Kristus, mereka malah menjadi marah. Menurut Yohanes Krisostomus, sebenarnya, mereka itu hendaknya membangun sebuah disposisi batin untuk memahami makna roti itu sendiri, yakni percaya. Kerinduan menyantap Roti itu didasarkan pada rasa percaya ( $\pi\llcorner\sigma \tau \epsilon \dot{\omega} \omega)$. Percaya itu membuahkan sikap seorang murid yang sejati, yakni tidak terlalu penasaran tentang pernyataan dari gurunya, tetapi mendengar dan menaati-Nya, dan menunggu waktu yang tepat untuk solusi dari beragam kesulitan (Hom 45.2.XXII).Jadi, dari ulasan dalam homili ke-45 ini, tampak adanya sebuah tegangan antara kata kebodohan dan percaya dalam memahami makna roti itu sendiri.

\subsubsection{RotiMengantar pada Kebangkitan}

Dalam homili ke-46, ia masuk dalam misteri Roti yang semakin mendalam. Semakin terang, bahwa Sang Roti itu adalah Kristus sendiri. Namunkarena kebodohannya, para pendengar Yesus tidak memahami misteri ini dan mereka sibuk untuk bersungut-sungut serta mempertanyakan identitas Yesus yang mereka lihat semata sebagai anak Yusuf. Dalam kontras dengan sikap bersungut-sungut dan mempertanyakan siapa Yesus, Yohanes Krisostomus mulai masuk dalam penegasan bahwa Roti itu adalah Kristus, Sang Anak Allah sendiri. Di sini, gagasan bersungutsungut menjadi satu tahapan tersendiri untuk memahami misteri roti itu sendiri.
Yohanes Krisostomustak lagi semata berbicara tentang arti kata Roti, tetapi ia mulai masuk dalam misteri Roti itu. Ia menegaskan bahwa yang percayadalam misteri Roti ini akan dibangkitkan pada akhir zaman (Yoh 6:44). Penjelasan misteri Roti itu semakin meningkat. Roti itu tidak hanya membuat seseorang tidak lagi lapar atau haus (Yoh 6:35), tetapi mengantar seseorang pada keselamatan, pada sebuah kebangkitan pada akhir zaman. Lalu, apakah Roti yang dimaksud oleh Yesus itu? Menurut Yohanes Krisostomus,
Ia menyebut diri-Nya, (ayat 48) "roti hidup," karena Ia memelihara hidup kita baik hidup yang sedang kita jalani dan hidup yang akan datang, dan berkata, "Barangsiapaakan makan roti ini akan hidup

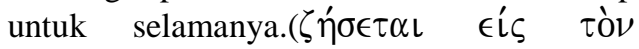 $\alpha \iota \hat{\omega} \nu \alpha)$ " Dengan "roti", Ia menujukan perkataan-Nya di sini baik sebagai doktrin (ajaran)-Nya tentang keselamatan sekaligus iman seseorang kepada-Nya, atau kepada

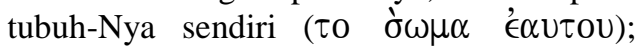 keduanya saling terkait satu sama lain. Namun, di tempat lain, Ia berkata, "Jika seseorang mendengarperkataan-Ku, Ia tidak akan pernah mengalami maut." (Yoh 8:51). Dan mereka tersinggung

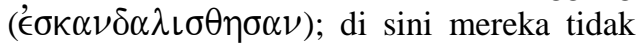 memiliki perasaan yang tepat mungkin karena mereka masih belum menghormati- Nya karena roti yang telah Ia buat. (Hom 46.1.XX).

Dari pernyataan Yohanes Krisostomus ini, muncul permasalahan lagi yang bisa dikritisi, yaitubagaimana kemudian menjelaskan ayat 51 yang menegaskan bahwa Roti yang diberikan oleh Kristus itu adalah daging-Nya demi hidup dunia? Yang menarik adalah Yohanes Krisostomus berbicara tentang Rotiyang menyelamatkan itu terkait erat dengan kata daging dan darah. Dalam cara pandang Kristiani saat ini, tentunya kedua kata ini langsung mengantar seorang Kristiani pada misteri perjamuan tubuh dan darah Kristus. Tetapi, apakah memang itu maksudnya?

Menken mengatakan bahwa penjelasan ayat 51 ini harus dipahami dengan sebuah rasa metaforis. Makan roti yang merupakan dagingNya itu sejajar dengan percaya pada Yesus. Pada titik ini, Menken mengatakan bahwa misteri Roti yang ditawarkan oleh penginjil Yohanes tidak pertama-tama berbicara tentang Ekaristi, tetapi sebuah pernyataan Kristologis. ${ }^{15}$ Menken mengatakan dengan tegas bahwa Roti yang disebut dalam ayat 51 itu bukanlah roti ekaristis, 
tetapi Roti Hidup yang menjadi identifikasi Pribadi Yesus sendiri. ${ }^{16}$

Pandangan Menken ini bisa menjadi sebuah pembanding bagi pandangan Yohanes Krisostomus. Yang jelas dapat dilihat pertama-tama adalah bahwa Menken melihat ayat 51c sebagai awal dari rangkaian ayat 51c-58. Namun, Yohanes Krisostomus melihat ayat 51c ini sebagai sebuah kesatuan dari ayat 41-52 (homili ke-46). Di sini, tampak bahwa memang bagi Yohanes Krisostomus, misteri Roti yang dimaksud itu adalah diriNya sekaligus perintah-perintah-Nya. Namun, pada saat yang bersamaan, ayat 51 mengantar para pendengar Yohanes Krisostomus untuk memandang misteri Roti itu sebagai daging dan darahNya. Jadi, Yohanes Krisostomus meleburkan dua tema yang digagas oleh Brown terkait dengan ulasan ini, antara tema hikmat pribadi Yesus dan tema sakramental yang mengarah pada gagasan Ekaristi. $^{17}$

Memang, disadari bahwa dalam perspektif hidup beriman Kristiani, pernyataan Yohanes Krisostomus

tetapi Aku," demikianlah kata-Nya, "tidak begitu, Aku memberimu makan dengan daging-Ku sendiri, yang menginginkan agar kamu semua akan lahir mulia (kelahiran kembali),dan memeluk erat kamu semua dalam harapan cerah bagi masa depan. (Hom 46.3.XXIII)

mengingatkan para pembaca akan gagasan ekaristi. Di sini pula, tak hanya kata daging, tetapi kata darah dimunculkan sebagai yang menyucikan dan menyegarkan jiwa dan seluruh dunia.

Pada bagian keempat homili ke-46 ini, gagasan ekaristi itu semakin tegas dengan adanya sebuah sikap tegas dan kesediaan menyantap daging dan darah-Nya (Hom 46.4.XXV). Kesediaan menyantap daging dan darah-Nya itu akan membuahkan hasil yang berlimpah, yakni

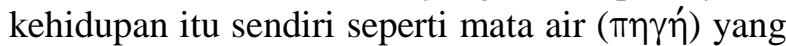
hidupi setiap tempat yang dilalui oleh aliran airnya (Hom 46.4.XXIV). Daging dan darah-Nya itu menjadi misteri Gereja yang dahsyat (Hom 46.4.XXIV). Pernyataan misteri Gereja dan dahsyatnya bisa dengan mudah dibaca oleh pembaca Kristiani saat ini sebagai misteri ekaristi.

Lalu, jika dipertegas lagi, apakah Roti yang dimaksud oleh Yohanes Krisostomus terkait dengan kata kebangkitan, daging, darah, dan mata air? Penulis melihat pandangan Moloney bisa membantu untuk mempertegas jawabannya. Moloney mengatakan, kata daging dan darah dalam ayat 50 dan seterusnya itu pertama-tama menekankan akan hidup yang inkarnatif dan kematian real dari Sang Anak yang merupakan makanan yang memberikan hidup. Hanya tubuh fisik dari manusia yang bisa memproduksi daging dan darah. ${ }^{18}$ Penulis melihat, Yohanes Krisostomus menekankan dimensi inkarnasi Yesus sebagai sungguh-sungguh manusia yang berdaging dan berdarah. Inkarnasi itu mengantarkan pada pengurbanan yang membawa manusia pada kebangkitan itu sendiri. Jadi, di sini, tampak bahwa ada dua tekanan yang bersamaan dimunculkan oleh Yohanes Krisostomus tentang misteri Roti itu sendiri, yakni tentang diri Yesus sendiri bersamaan dengan segala perintahperintah-Nya dan pada saat yang bersamaan diri Yesus itu nyata dalam daging dan darah-Nya yang dikenangkan dalam ekaristi.

\subsubsection{Rotiitu Kristus}

Jika dipertegas kembali pertanyaannya, apakah misteri Roti itu mengacu pada Kristus atau Ekaristi? Atau, apakah diskursus roti hidup ini merupakan sebuah kristologi atau teologi ekaristi? Pertanyaan kedua ini merupakan pertanyaan Menken atas ayat 51c-58. Dan, jawabannya adalah bahwa teks itu pertama-tama merupakan sebuah kristologi, sebuah penegasan akan identitas Yesus sendiri. ${ }^{19}$ Namun, jika cakupan teks yang diulas diperluas dan juga melihat homili ke-47 sebagai homili pamungkas tentang Roti Hidup, apa kiranya jawaban Yohanes Krisostomus?

Di sini, penulis berangkat dari beberapa hal yang menarik. Pertama, dalam dinamika intensitas kemunculan kata roti, di homili ke-47, kata roti muncul paling sedikit (hanya 4 kali). Dalam pendekatan tipologis, tampak bahwa Yohanes Krisostomus mulai meninggalkan kata roti itu dan menggantikannya dengan kata Kristus yang muncul sebanyak 13 kali dalam homili ini. Dari data ini tampak bahwa memang roti itu tidak lagi menjadi penting, tetapi yang penting adalah Kristus sendiri.

\begin{tabular}{|c|c|c|c|c|}
\hline \multirow[b]{2}{*}{ Homili } & \multicolumn{3}{|c|}{ Kata "Kristus" } & \multirow[b]{2}{*}{ Jumlah } \\
\hline & $\begin{array}{c}\text { Kutipan } \\
\text { Kitab } \\
\text { Suci }\end{array}$ & Homili & $\begin{array}{c}\text { Rumusan } \\
\text { Doa }\end{array}$ & \\
\hline 44 & - & 4 & 1 & 5 \\
\hline 45 & - & 7 & 1 & 8 \\
\hline 46 & - & 7 & 1 & 8 \\
\hline 47 & - & 12 & 1 & 13 \\
\hline
\end{tabular}

Tabel Intensitas Kata "Yesus” 


\begin{tabular}{|c|c|c|c|c|}
\hline \multirow[b]{2}{*}{ Homili } & \multicolumn{3}{|c|}{ Kata "Yesus" } & \multirow[b]{2}{*}{ Jumlah } \\
\hline & $\begin{array}{c}\text { Kutipan } \\
\text { Kitab } \\
\text { Suci } \\
\end{array}$ & Homili & $\begin{array}{c}\text { Rumusan } \\
\text { Doa }\end{array}$ & \\
\hline 44 & 1 & 6 & 1 & 8 \\
\hline 45 & 1 & - & 1 & 2 \\
\hline 46 & 1 & - & 1 & 2 \\
\hline 47 & 4 & 1 & 1 & 6 \\
\hline
\end{tabular}

Tabel Intensitas Kata "Yesus"

Kedua,kata hikmat ( $\sigma 0 \phi i ́ \alpha)$ ini muncul begitu saja dan menarik untuk dicermati jika dilihat dalam konteks yang lebih luas. Jika mencermati konteks penulisan homili ini sendiri, C. Baur mengatakan, homili atas Injil Yohanes ini secara keseluruhan dibuat untuk mendamaikan perselisihan pandangan iman, khususnya terkait dengan Arianisme yang menggelisahkan umat beriman. $^{20}$ Arius berusaha untuk menjelaskan pribadi Kristus dalam perspektif filsafat Yunani dan erat sekali mengkaitkannya dengan kata hikmat. Di sisi lain, Brown mengatakan, pernyataan diri Yesus sebagai hikmat itu merupakan sebuah penyingkapan dari apa yang dinyatakan dalam Perjanjian Lama. Menurut Brown, penginjil Yohanes sendiri memang memberikan sebuah keterkaitan antara '̇ $\gamma \omega \dot{~}$

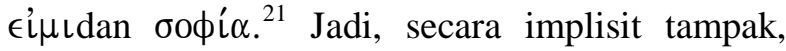
gagasan hikmat dimunculkan oleh Yohanes Krisostomusdalam homili-homilinya inisebagai pintu masuk berhadapan dengan Arianisme untuk menegaskan keilahian Kristus sendiri.

Ketiga,muncul gagasan hidup kekal ( $\zeta \omega \eta$ $\alpha i \omega \nu$ íos). Yohanes Krisostomus menegaskan, hidup kekal ini merupakan buah yang dinikmati oleh orang-orang yang percaya kepada Kristus. Hidup kekal merupakan sebuah kebersamaan dan hidup dalam Yesus. Pengakuan dan iman akan identitas Yesus sendiri sebagai Kristus mengantar pada kebangkitan untuk hidup dalam persatuan dengan Allah. Yang menarik adalah gagasan dalam Yoh 17:3, "Inilah hidup yang kekal itu, yaitu bahwa mereka mengenal Engkau, satusatunya Allah yang benar, dan mengenal Yesus Kristus yang telah Engkau utus.”

Keempat,munculnya gelar-gelar Yesus yang menyertai kata Kristus, yakni Anak Manusia (viòs

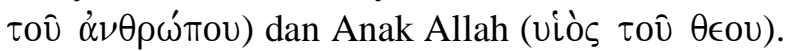
Menurut C.H. Dodd, gelar-gelar Anak Manusia dan Anak Allah itu merujuk pada gelar Kristus sendiri. Ketiga gelar ini saling terkait untuk menegaskan satu identitas, yakni Yesus Kristus. ${ }^{22}$
Keempat argumentasi di atas menegaskan dengan jelas bahwa misteri Roti itu mengarah pada penegasan identitas Yesus sebagai Kristus. Penegasan identitas itu juga menekankan dimensi keilahian Yesus dan kesehakikatan Yesus, Sang Anak, dengan Bapa. Tekanan pada kesehakekatan Yesus dengan Bapa bisa dipahami dari gagasan keselamatan dan hidup kekal itu sendiri. Jika Yesus tidak sehakikat dengan Bapa bagaimana mungkin Ia menjadi keselamatan bagi manusia dan membawa manusia kepada hidup kekal? Persis, di sinilah perbedaan dengan gambaran Arius yang menekankan bahwa Yesus itu merupakan perantara sebagai ciptaan pertama. Ia menjadi penghubung antara manusia dan Bapa. Namun, perlu disadari bahwa Yohanes Krisostomus bukanlah seorang teolog ataupun filsuf yang menekankan dimensi logika melulu dalam homilinya. Ia adalah seorang pertapa. Tampak bahwa akhirnya, Yohanes Krisostomus tak henti mengatakan bahwa yang diperlukan adalah cara pandang spiritual atau rohani agar sampai pada titik pengakuan identitas Yesus layaknya Petrus sendiri (6:69). Jika melihat semata-mata dengan kacamata duniawi, yang ada hanyalah roti yang mengenyangkan dan tidak dapat masuk dalam pengalaman transendental mengenali pribadi Kristus sendiri. Diakui, ada sisi keterbatasan manusiawi yang membuat manusia tidak mudah masuk dalam misteri ilahi pribadi Kristus yang sehakikat dengan Bapa.

\subsection{AkulahRoti Hidup: Kristus}

Berhadapan dengan Arianisme, teks Roti Hidup, bagi Yohanes Krisostomus, cukup berbicara banyak dalam upaya mempertahankan ajaran iman yang benar. Menurut penulis, titik pijaknya bisa dikenali dari problematika penerjemahan yang muncul dari ayat 69. Dalam teks Yohanes

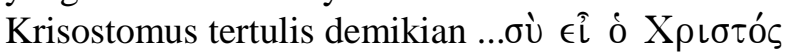

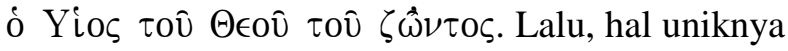
adalah jika menyandingkan dengan terjemahan dalam Kitab Suci Perjanjian Baru Terjemahan Baru edisi II. Yang ditulis dalam teks tersebut adalah "Engkaulah Yang Kudus dari Allah"23; padahal dalam teks Yohanes Krisos-tomus, yang tertulis itu berarti, "Engkaulah Kristus, Anak Allah yang hidup". ${ }^{24}$ Dalam teks Vulgata, yang tertulis berbeda lagi, yakni Christus Filius Dei (Kristus, Anak Allah). Dalam teks Vulgata, tidak tertulis kata keterangan "hidup". Ada dua dugaan yang penulis munculkan. Pertama, persoalan tekstual ini sangat mungkin disebabkan karena perbedaan sumber Kitab Suci yang diacu oleh Yohanes Krisostomus dan terjemahan lain. 
Yohanes Krisostomus mengguna-kan Teks Perjanjian Baru edisi revisi SyroConstantinopolitan. Kedua, Yohanes Krisostomus memiliki maksud lain dengan memunculkan kata Kristus secara eksplisit. Pandangan yang kedua ini rasanya bisa dikenali secara ilmiah dengan penelusuran konteks homili atas Injil Yohanes sendiri.

Selain itu, intensitas penggunaan kata Kristus yang dominan dalam keempat homili ini menjadi tanda yang khas bahwa Yohanes Krisostomus ingin mempertahankan ajaran iman yang benar. Misteri Roti yang dimaksud oleh Yohanes Krisostomus adalah Kristus sendiri. Ia menjelaskan dengan begitu cantiknya dalam untaian gagasan yang bertahap dari homili ke-44 sampai dengan ke-47. Di satu sisi, penulis melihat bahwa Yohanes Krisostomus menyadari bahwa teks Roti Hidup ini bukanlah sebuah teks yang mudah untuk dicerna oleh para pembacanya. Di sisi lain, ada kemendesakan untuk menyatakan iman yang benar akan Kristus itu sendiri yang sehakikat dengan Bapa. Di sini, Kristus seketika juga dapat dimengerti sebagai Anak Allah. Dan, persis pada gagasan Anak Allah inilah, Arianisme mempertanyakan identitas Anak Allah ini.

\subsubsection{Melawan Konsep Anak itu Diciptakan oleh Allah}

Arius menegaskan bahwa Sang Anak itu diciptakan oleh Allah Bapa. Dalam homili Roti Hidup ini, Yohanes Krisostomus memberikan perlawanan dengan memberikan pokok iman yang benar tentang Yesus, Sang Anak itu sendiri. Akulah roti yang turun dari surga (6:41). Dalam homili ke-46, dikatakan demikian,

... mereka seharusnya mendengarkan-Nya ketika Ia berkata, "Aku datang dari surga"; namun mereka tidak mendengarkan, tetapi bersungut-sungut. Mereka tetap menghormati-Nya karena karena mukjizat roti yang terjadi baru-baru ini, dan karena itu mereka tidak secara terbuka membantah-Nya, tetapi dengan bersungut-sungut...(Hom 46.1.XVIII).

Pernyataan Yohanes Krisostomus tegas,“Aku datang dari surga”. Ini menegaskan bahwa Roti itu adalah Yesus sendiri. Lebih dari itu, Sang Roti itu berasal dari surga, berasal dari Bapa sendiri. Permasalahannya adalah bahwa Orang-orang Yahudi yang mendengarkan Yesus tidak mendengarkannya, tetapi bersungut-sungut.

Di sini tampak bahwa Yohanes Krisostomus-bahkan Yesus sendiri-tidak mengatakan bah-wa Akulah roti yang diciptakan oleh Bapa. Tetapi, Akulah roti yang turun dari surga. Lalu, Yohanes Krisostomus menarik keterkaitan Roti yang turun dari surga itu dengan daging-Nya. Dalam ayat 51, dikatakan, "roti yang kuberikan itu adalah daging-Ku." Yohanes Krisostomus mengakui bahwa penjelasan ini tidak begitu mudah untuk dipahami. Ia menyatakan demikian,

... ajaran ini terasa aneh bagi mereka dan
tidak biasa." Dan, Yohanes pada waktu yang
sebelumnya telah menyinggung hal ini
dengan menyebut-Nya "Anak Domba." (Yoh
1:29) "Tetapi untuk kesemuanya itu, mereka
tidak mengetahuinya." Aku tahu bahwa
mereka tidak tahu; para murid juga tidak
mengerti... tidak salah satu dari mereka
pernah menegaskan bahwa ada orang yang
makan daging. Namun mereka mematuhi
dan mengikuti-Nya, dan mengakui bahwa
Dia memiliki perkataan hidup kekal. Karena,
ini merupakan bagian dari diri seorang
murid, tidak terlalu penasaran tentang
pernyataan dari gurunya, tetapi mendengar
dan menaati-Nya, dan menunggu waktu
yang tepat untuk solusi dari beragam
kesulitan. (Hom 46.2.XXII).

Penyadaran betapa tak mudahnya memahami misteri ini diimbangi dengan sebuah sikap murid sejati yang mendengar dan menaati-Nya, dan menunggu waktu yang tepat untuk solusi dari beragam kesulitan. Dalam bagian sebelumnya, telah dinyatakan bahwa gambaran daging itu menunjukan gambaran inkarnasi Anak menjadi manusia yang berdaging dan berdarah. Menyantap roti-Nya yang adalah daging-Nya itu tentunya mengigatkan akan gagasan Ekaristi. Dalam ekaristi bukan hanya inkarnasi yang dikenangkan dan dirayakan, tetapi sengsara, wafat, dan kebangkitan-Nya.

Disposisi tegas Yohanes Krisostomus adalah meyakini bahwa Roti itu turun dari surga demi keselamatan manusia. Roti tidak mungkin berasal dari manusia. Di sini, ditegaskan, sesungguhnya Yesus, Sang Anak itu dari Allah. Keilahian-Nya tidak diragukan sekaligus tak diragukan pula bahwa Ia tidak diciptakan oleh Allah. Kalau Ia diciptakan oleh Allah, berarti ada 'saat' di mana Sang Anak itu tidak ada. Inilah keberatan kedua yang dilawan oleh Yohanes Krisostomus.

\subsubsection{Melawan Konsep Ada 'Saat' di mana Anak itu Tidak Ada}

Engkau memiliki perkataan ( $\dot{\eta} \eta \mu \alpha \tau \alpha)$ hidup yang kekal." Orang-orang ini sudah 
mengakui kebangkitan, dan semua pembagian adil yang akan berada di sana. Dan perhatikan orang yang hidup dalam persaudaraan dan kasih sayang, bagaimana ia dapat menjadi jawaban bagi semua anggotanya. Karena ia tidak mengatakan, "saya tahu," tetapi, "kami tahu." Atau lebih tepatnya, perhatikan bagaimana ia terarah pada perkataan-perkataan pokok dari Gurunya, tidak berbicara seperti yang dilakukan orang-orang Yahudi. Orang Yahudi berkata, "Inilah anak Yusuf", tetapi ia berkata, "Engkau adalah Mesias, Anak Allah yang hidup", dan "Engkau memiliki perkataan hidup kekal”, setelah mendengar mungkin Ia berkata, "barangsiapa yang percaya pada-Ku (Nya - Sang Putera) beroleh hidup yang kekal, dan Aku akan membangkitkannya pada hari terakhir. (Hom 47.3.XXXV-XXXVI)

Kutipan di atas menjadi begitu jelas akan sebuah apologi atas gagasan ada 'saat' di Anak itu tidak ada. Pengakuan iman akan Pribadi Yesus sebagai yang memiliki perkataan itu mengantar pada realitas kenyataan sang Sabda yang ada sedari awal penciptaan. Yohanes Krisostomus agak sedikit menggunakan permainan kata antara Kristus (Mesias) dan kata $\dot{\rho} \eta \mu \alpha$ itu sendiri. Inilah yang membantu pemahaman akan iman yang benar tentang Krisus sendiri.

Menurut Bornkamm, kata $\rho \hat{\eta} \mu \alpha$ dan $\lambda$ óyockerap ditampilkan bersamaan seiring dengan kata $\lambda^{\prime} \epsilon \omega$ dan $\lambda \alpha \lambda^{\prime} \epsilon \omega$. Günther Bornkamm juga menjelaskan bahwa kataṕn $\mu \alpha$ dan $\lambda o ́ \gamma o \varsigma$ dalam literasi Yunanimemiliki arti yang sama, yakni kata atau sabda. Dicatat bahwa dalam Perjanjian Lama, kata $\hat{\eta} \mu \alpha$ muncul 29 kali dan kata $\lambda$ ó 20 kali (91). Dalam Perjanjian Baru pun tidak ada

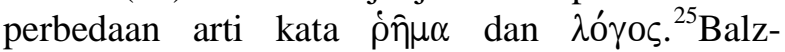

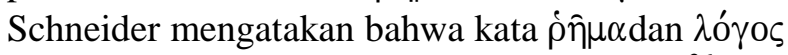
berasal dari kata Ibrani yang sama, $d \bar{a} b \bar{a} r .{ }^{26} \mathrm{Kata}$

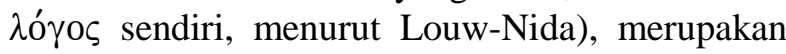
gelar Yesus dalam Injil Yohanes yang menjadi acuan pada perwahyuan Allah dan sebagai sebuah gema verbal dari penggunaan kata-kata yang berarti “Allah yang bersabda” dalam Kejadian bab pertama (Yoh 1:14). ${ }^{27}$

Jadi, bisa dilihat dengan jelas bahwa pernyataan Yohanes Krisostomustentang ayat 68 ini mengingatkan para pembaca akan kisah penciptaan, Allah yang bersabda. Jadi, pernyataan Petrus dalam ayat 68 itu menegaskan bahwa Yesus adalah perkataan hidup dan kekal. Di sini, ingin ditampilkan kesadaran pokok, yakni bahwa Yesus, Sang Sabda yang merupakan Sang Anak itu pula, ada sejak awal mula, bahkan sebelum penciptaan. Ia ada bersama dengan Bapa. Jadi, tidak ada saat di mana Ia tidak ada. Penegasan ini semakin meruncingkan gagasan dasar tentang kesehakikatan Anak dengan Bapa.

\subsubsection{Menegaskan Anak Sehakikat dengan Bapa}

Arius mengajarkan bahwa konsekuensi logis bahwa Sang Anak itu bukanlah Allah dan Sang Anak juga bukanlah manusia, adalah Anak itu tidak sekakikat dengan Bapa.Dalam keempat homili, ada tiga argumentasi yang menjadi bisa dikenali sebagai apologi Yohanes Krisostomus atas Arianisme. Pertama, setelah mencermati intensitas kemunculan kata Yesus dan kata Kristus dalam keempat homili, tampak sekali bahwa kata Kristus jauh lebih dominan muncul daripada kata Yesus. (lih. Tabel Intensitas Kata "Yesus" dan Kata "Kristus" di bagian 3.1.4.). Di sini, tersirat makna bahwa gelar Kristus yang dimunculkan oleh Yohanes Krisostomus ingin menekankan dimensi keilahian dan kesehakikatan Sang Anak itu dengan Bapa-Nya.Kedua, ketika mengawali penjelasan tentang ayat 57- "Sama seperti Bapa yang hidup mengutus Aku dan Aku hidup oleh Bapa" dalam homili ke-47, Yohanes Krisostomus menyatakan demikian,

... Kemudian Ia berkata, "Seperti Bapa yang
hidup mengutus Aku." Ini adalah ekspresi
perbandingan dan persamaan ${ }^{28}$, dan artinya
adalah semacam ini, "Aku hidup
sebagaimana Bapa hidup." Dan supaya
engkau tidak menganggap-Nya tidak
diperanakkan, ${ }^{29}$ Ia dijadikan, ${ }^{30}$ "oleh Bapa,"
hal ini tidak menunjukkan bahwa Ia
memerlukan, setiap kekuatan ilahi ${ }^{31}$ dalam
diri-Nya untuk hidup, karena Ia mengatakan
sebelumnya, untuk menghilangkan seperti
kecurigaan, "Seperti Bapa memiliki hidup
dalam diri-Nya, sehingga Ia memberikannya
kepada Putra juga agar memiliki hidup
dalam diri-Nya"... (Hom 47.1.XXVIII).

Pernyataan bahwa "Aku hidup sebagaimana Bapa hidup” menegaskan bahwa senyatanya Sang Anak itu mengambil bagian dari Bapa dan Ia sungguh dilahirkan, bukan dijadikan. Inilah penegasan dimensi keilahian Yesus dan kesehakikatanNya dengan Bapa. Ketiga, pengakuan Petrus dalam ayat 68 yang kemudian dijelaskan oleh Yohanes Krisostomus dalam homili ke-47 membantu untuk menjelaskan Sang Anak yang sehakikat dengan Bapa. Dalam homili tersebutdikatakan,

Orang Yahudi berkata, "Inilah anak Yusuf", tetapi ia berkata, "Engkau adalah Mesias, 
Anak Allah yang hidup", dan "Engkau memiliki perkataan hidup kekal”, mungkin setelah mendengar Ia berkata, "barangsiapa yang percaya pada-Ku (Nya - Sang Putera) beroleh hidup yang kekal, dan Aku akan membangkitkannya pada hari terakhir." Karena ia menunjukkan bahwa ia mempertahankan semua yang telah dikatakan, dengan mengulang kembali perkataan-Nya. (Hom 47.3.XXVI)

Petrus tidak memandang Yesus secara manusiawi belaka, tetapi ia mampu melihat secara utuh kenyataan diri Yesus dengan iman dan kepercayaaannya. Ada pribadi yang menyatakan diri di balik diri seorang anak Yusuf. Tekanan Yohanes Krisostomus adalah bahwa Yesus itu adalah Kristus, Anak Allah yang hidup. Frasa "Engkau adalah" menujukkan sebuah pengakuan yang langsung diutarakan di hadapan subjek yang dimaksud.

Jadi, Yohanes Krisostomus mengantar para pendengarnya pada pengalaman iman yang personal layaknya Petrus sendiri. Yohanes Krisostomus mengajak para pendengarnya masuk dalam misteri Roti itu secara personal,karena, ketika mereka hanya mengikuti arus dan berpikir seperti manusia biasa, mereka tidak akan sampai pada penghayatan rohani akan identitas Yesus. Bahkan, secara ekstrim bisa dikatakan bahwa jika mereka semata mengikuti arus yang ada, seperti yang diyakini oleh orang-orang Goth, iman mereka akan Kristus semakin merosot karena penuh keraguan seperti orang-orang Yahudi pada zaman Yesus.

Pengalaman iman personal ini sebenarnya bermuara pada keselamatan dan hidup kekal. Dalam iman akan Kristus, Sang Anak Allah, ada keselamatan dan kebangkitan. Petrus mengakui hal ini dengan tegas dalam ayat 68. Bagi Yohanes Krisostomus, ini menjadi titik terang iman yang diperlukan bagi para pendengarnya. Sebuah keyakinan bahwa keselamatan itu berasal dari Allah Bapa dan dari Sang Anak yang diutus oleh Bapa (Yoh 17:3).

Dari kerinduan dan harapan akan keselamatan dan kebangkitan untuk hidup kekal, tampak jelas bahwa kedatangan Yesus ke dunia sebagai Roti Hidup itu menawarkan kerinduan itu sendiri bagi manusia. Jadi, bisa dicermati bahwa penegasan identitas Yesus sebagai Roti itu tidak lepas dari gagasan Yesus sebagai Kristus dan Anak Allah. Lebih dari itu, gagasan identitas Yesus ini, menurut Yohanes Krisostomus, tidak lepas dari visi keselamatan yang disampaikan Yesus bagi manusia. Penegasan tentang pribadi Yesus ini tidak lepas dari pembicaraan tentang keselamatan dan hidup kekal.

Di sini semakin tampak bahwa apa yang dibahas dalam homili ke-46 bagian 3 dan 4, terkait dengan gagasan daging dan darah-Nya itu, memberikan penegasan bahwa dalam perjamuan di meja itu bisa dimengerti sebagai Ekaristi. Yesus adalah kurban Ekaristi demi keselamatan manusia. Pengurbanan-Nya mengantar pada keselamatan bagi manusia. Daging dan darah-Nya memberikan kehidupan dan manusia yang menantap-Nya dipersatukan dengan diri-Nya dalam satu Tubuh dengan-Nya (Hom 46.2-3).

Jadi, secara umum bisa dipahami bahwa Roti Hidup dipahami dapat sebagai Yesus, dan sekaligus Roti hidup itu merujuk pada daging dan darah Kristus. Dengan menyantapnyadalam arti literalmanusia disatukan dengan Kristus sendiri dan diselamatkan. Dalam pemahaman diselamatkan dan dibangkitkan untuk hidup kekal itu sendiri, nyata kesehakikatan Anak dan Bapa. Dalam pemikiran sederhana, bagaimana mungkin jika tidak sehakikat dengan Bapa, Anak bisa menyelamatkan manusia dan membangkitannya? Bagaimana mungkin jika tidak sehakikat dengan Bapa, manusia bisa mengalami kebangkitan untuk hidup dengan menyantap daging dan darah-Nya? Kesehakikatan dengan Bapa semakin dipertegas dengan gagasan ekaristi yang dikembangkan oleh Yohanes Krisostomus, khususnya dalam homili ke-46 ini sehingga jelaslah pengakuan iman yang benar bahwa Yesus, Sang Anak itu sehakikat dengan Bapa.

\section{PENUTUP}

Roti Hidup itu teologi Ekaristi atau Kristologi? Jika dicermati dari seluruh ulasan yang disajikan dan konteks pembicaraan sebagai apologi melawan Arianisme Roti Hidup itu menegaskan identitas Yesus sendiri sebagai Anak Allah yang sehakikat dengan Bapa-Nya. Inilah pokok iman Konsili Nikea yang dipertahankan dan diwartakan oleh Yohanes Krisostomus.

Di dalam gagasan tentang identitas Yesus ini, Yohanes Krisostomus juga memberikan penjelasan tentang daging dan darah-Nya yang khas identik dengan Ekaristi. Namun, gagasan Ekaristi tetap harus dilihat dalam rangka kristologi. Gagasan ekaristi berada di dalam rangkaian ulasan tentang identitas Yesus yang sehakikat dengan Bapa-Nya. Yang lebih penting dari itu semua adalah gagasan keselamatan dan kebangkitan untuk hidup kekal. Inilah muara dari pengakuan identitas Yesus sendiri dan gagasan ekaristi yang 
termaktub di dalamnya. Gagasan kristologis yang diangkat oleh Yohanes Krisostomus ini tak bisa dilepaskan dari gagasan tentang soteriologi. Sebaliknya, bisa dimengerti dengan jelas bahwa Yohanes Krisostomus melawan ajaran Arianisme dengan memberikan penegasan tentang Roti hidup yang memberikan kehidupan kekal. Roti itu adalah daging-Nya sendiri. Roti hidup itu adalah Diri-Nya sendiri yang turun dari surga. Hanya dalam Roti itulah keselamatan diwartakan dan dimiliki oleh manusia.

Jadi pada pokoknya keempat homili Yohanes Krisostomus ini berbicara tentang Kristologi, berbicara tentang identitas Yesus sendiri. Roti menjadi sebuah 'typos'yang mengantarkan para pendengarnya memahami bahwa di balik misteri Roti itu, ada pribadi Yesus yang dinyatakan dan di balik gagasan misteri Ekaristi itu, ada pribadi Yesus yang luhur dan mulia yang diwartakan dan diimani. Harapan Yohanes Krisostomus adalah agar para pendengarnya semakin percaya pada Yesus dan tidak lagi meragukan-Nya. Semuanya itu mungkin ketika manusia hidup dalam iman dan penuh kepercayaan serta tidak melulu berpikir dengan cara pikir manusiawi, tetapi berpikir dan melihat dengan cara pandang spiritual.

\section{Antonius Baur Asmoro}

Rohaniwan dan pemimpin jemaat di Paroki St. Maria Regina Bintaro Jaya; Alumnus Program Magister Teologi Universitas Sanata Dharma.

\section{CATATAN AKHIR}

Menurut Nico Syukur Dister, Injil Yohanes tak mudah dipahami karena jika menelusuri konteks penulisannya, Injil ini ditulis pada masa penganiayaan. Tampak jelaslah bahwa di dalam penderitaan akan penganiayaan itu, ada kerinduan akan sebuah kehidupan spiritual dan hal-hal rohani yang melampaui dunia fisik. (N. Syukur Dister, Teologi Sistematika II, Kanisius, Yogyakarta 2004, 223-224).

2 E. Martasudjita, Ekaristi: Tinjauan Teologis, Liturgis, dan Pastoral, Kanisius, Yogyakarta 2005, 243-247.

3 Jo-Anna A. Brant, John, Baker Academic, Grand Rapids 2011, 127.

4 Yohanes Krisostomus lahir pada tahun 349 di Antiokhia, Syria (sekarang daerah Antakya di Turki Selatan). Ia lahir dari sebuah keluarga Kristiani.Karena ayahnya meninggal pada saat ia masih kecil, pendidikan awalnya diterima dari Anthousa, ibunya yang begitu saleh. Ia menjalani masa pendidikan lanjutnya di bawah bimbingan Libanius, orang kafir dan ahli pidato yangpaling terkenal pada jamannya. Bersama Libanius, Yohanes pun mengikuti pelajaran filsafat dan retorika. Tahun 368, Yohanes dibaptis dan kemudian dididik oleh Uskup Meletius, Uskup Antiokhia, untuk memperdalam kehidupan gerejawi. Kemudian, ia diangkat menjadi lektor dalam tahun 371. Pada tahun 367-372, ia mengikuti Asketerium, semacam seminari, di Antiokhia di bawah bimbingan Diodorus dari Tarsus. Pada tahun 381, ia ditahbiskan menjadi diakon oleh Meletius dan ditahbiskan menjadi imam oleh Uskup Flavianus pada tahun 386. Pada tahun
397 ia diangkat menjadi Uskup Konstantinopel. Tahun 403 ia dipecat dari jabatan uskup oleh Sinode yang diadakan oleh Patriarkh Theophilus dari Alexandria. Sekembalinya dcari pembuangan ia tetap setia memperjuangkan kebenaran iman, sehingga tahun 406 ia mengalami pembuangan lagi. Ia meningga pada tanggal 14 September 407. Dia meninggalkan 17 risalah, lebih dari 700 homili, dan 241 surat.

5 J. Quasten menegaskan bahwa homili Yohanes Krisostomus atas Injil Yohanes merupakan homili eksegetis karena berisi tentang eksegese atas Injil tersebut. Hampir semua homili Yohanes Krisostomus merupakan homili eksegetis karena berisi tentang eksegese terhadap Kitab Suci Perjanjian Pertama ataupun Kitab Suci Perjanjian Baru. (J. Quasten, Patrology, Vol. III, The Newman Press, Maryland, 1960, 433).

6 Secara keseluruhan, homili Yohanes Krisostomus yang mengulas tentang Injil Yohanes ada delapan puluh delapan (88) homili. Homili atas Injil Yohanes bab VI adalah homili ke-42 sampai dengan ke-47. Homili ini merupakan homili terbanyak ketiga dari sisi jumlah tulisannya — setelah homili atas Injil Yohanes bab I dan bab III- dalam keseluruhan homili Yohanes Krisostomus atas Injil Yohanes. Dan, yang secara khusus mengulas tentang Roti Hidup adalah homili ke-44 sampai dengan ke-47.

Quasten, Patrology, 439.

8 John Chrysostom, The Homilies of St. John Chrysostom on The Gospel of St. John, translated by Philip Schaff, diunduh dari www.ccel.org/ccel/schaff/npnf114.html

9 J.-P. Migne, Patrologiae Cursus Completus, Patrologiae Graecae Tomus LIX: S. Joannes Chrysostomus, Bibliothecae Cleri Universae, Montrouge1859, 247-270.

10 Dalam homili ke-44, kata roti muncul sebanyak 5 kali. Dalam homili ke-45, muncul 26 kali. Dalam homili ke-46, kata ini muncul sebanyak 18 kali. Dalam homili ke-47, muncul 4 kali. Kata roti yang kami cantumkan ini, termasuk kata roti yang dikutip dari teks Yohanes sendiri yang dimunculkan oleh Yohanes Krisostomus dalam homilinya.

11 Pius XII, Divino Afflante Spiritu (30 September 1943), diakses dari

http://www.vatican.va/holy_father/pius_xii/encyclicals/document s/hf_p-xii_enc_19430930_divino-afflante-spiritu_lt.html, (18 Januari 2013).

12 S. Hylen, Allusion and Meaning in John 6, Walter de Gruyter, New York, 2005, 3.

13 Raymond Bailey mengatakan bahwa usaha Yohanes Krisostomus menarik korelasi Perjanjian Lama dan Perjanjian Baru serta membangun sebuah konteks sejarah dikenali dengan istilah tipologi. Tipologi mengasumsikan korespondensi intensional, keterkaitan antara pribadi dan peristiwa-peristiwa dalam Perjanjian Lama dan Perjanjian Baru. Tipologi itu mengidentifikasikan gagasan-gagasan yang implisit dalam Perjanjian lama menjadi gagasan-gagasan yang eksplisit dalam Perjanjian Baru. Yang dinyatakan samar-samar dalam Perjanjian Lama mendapatkan pencerahan makna dalam Perjanjian Baru. [R. Bailey, "Hermeneutics: A Necessary Art” dalam Hermeneutics for Preaching; Approaches to Contemporary Interpretational of Scripture, Raymond Bailey (ed.), Broadman Press, Nashville, 1992,15.]

14 S. Hylen, Allusion and Meaning in John 6, 5.

15 M.J.J. Menken, “John 6:51c-58: Eucharist or Christology?”, in Critical Reading of John 6, edited by R. Alan Culpepper, Brill, Leiden-New York-Köln, 1997, 184.

16 M.J.J. Menken, “John 6:51c-58: Eucharist or Christology?”, 201.

17 R.E. Brown, The Gospel According to John (i-xii), Doubleday \& Company, Inc., Garden City, New York 1966,272-274.

18 F.J. Moloney, The Gospel of John, Sacra Pagina Series, Vol 4, The Liturgical Press, Collegeville, Minnesota, 1998, 221.

19 M.J.J. Menken, “John 6:51c-58: Eucharist or Christology?”, 201.

20 C. Baur, John Chrysostom and His Time Vol. I; Antioch, Sands \& Co. LTD, London, 1960, 290.

21 R.E. Brown, The Gospel According to John (i-xii), CXXII. 
22 C.H. Dodd, The Interpretation of The Fourth Gospel, The Syndics of The Cambrige University Press, Cambrige 1954, 230.

23 Menurut C.H. Dodd, Yang kudus dari Allah itu berarti Kristus (ayat 69) - (C.H. Dodd, The Interpretation of The Fourth Gospel, 228).

24 Dalam Kitab Suci Perjanjian Baru bahasa Yunani versi United Bible Societies (UBS) yang tertulis adalah o` a[gioj tou/ qeou/ (Yang Kudus dari Allah).

25 Günther Bornkamm, " $\lambda \epsilon ́ \gamma \omega$ ” in Theological Dictionary of the New Testament, ed. Gerhard Friedrich, trans. and ed. Geoffrey W. Bromiley, vol. 4, Wm. B. Eerdmans Publishing Company, Grand Rapids, 1971, 105.

26 Horse Balz and Gerhard Schneider, Exegetical Dictionary of The New Testament,Vol II, William B. Eerdmans Publishing Company, Michigan, 1990, 357.

27 J.P. Louw and E.A. Nida, Greek-English Lexicon of the New Testament; Based on Semantic Domains, Vol. I-II, United Bibles Societies, New York, 1988, 400).

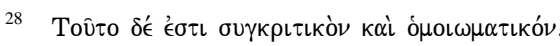

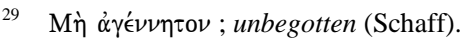

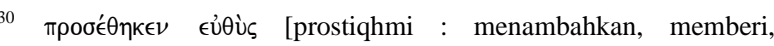
menderma] ; subjoineth (Schaff).

$31 \quad \epsilon \nu \in \rho \gamma \epsilon i \alpha \varsigma$ [' $\epsilon \in \rho \gamma \epsilon i \alpha$ : pekerjaan, kekuatan (supranatural)] ; Any power working in Him (Schaff).

\section{DAFTAR RUJUKAN}

Bailey, R., 1992, "Hermeneutics: A Necessary Art” dalam Hermeneutics for Preaching; Approach-es to Contemporary Interpretational of Scripture, Raymond Bailey (ed.), Nashville: Broadman Press.

Balz, Horse, and Gerhard Schneider, 1960, Exegetical Dictionary of The New Testament, Vol II, Baur, C., John Chrysostom and His Time Vol. I; Antioch, London: Sands \& Co. LTD.

Baur, C., John Chrysostom and His Time Vol. II; Constantinople, Sands \& Co. LTD, London

Friedrich, trans. and ed. Geoffrey W. Bromiley, 1971, vol. 4, Wm. B. Eerdmans Publishing Compa-ny, Grand Rapids.

William B. Eerdmans, 1990, Michigan: Publishing Company.

Benedict XVI, 2008,Church Fathers; From Clement of Rome to Augustine; General Audiences 7 March 2007 - 27 February2008, San Fransisco: Ignatius Press.

Bornkamm, Günther, 2011, “ $\lambda \epsilon ́ \gamma \omega ”$ in Theological Dictionary of the New Testament, ed. Gerhard Brant, Jo-Anna A.,John, Baker Academic, Grand Rapids.

Brown, R.E.,1966, The Gospel According to John (i-xii), Doubleday \& Company, Inc., New York: Garden City.

Chrysostom, John,The Homilies of St. John Chrysostom on The Gospel of St. John, translated by Philip Schaff, diunduh dari www.ccel.org/ccel/schaff/npnf114.html
Dister, N. Syukur, 2004, Teologi Sistematika II, Yogyakarta: Kanisius.

Groenen, C., 1988, Sejarah Dogma Kristologi; Perkembangan Pemikiran tentang Yesus Kristus pada Umat Kristiani, Yogyakarta: Kanisius.

Hall, Christopher A.,2002, Learning Theology with The Church Fathers, Illinois: InterVarsity Press.

Harmless, W., 2004, Desert Christians; An Introduction to the Literature of Early Monasticism, , New York:Oxford University Press.

Hylen, S.,2005, Allusion and Meaning in John 6,New York:Walter de Gruyter.

Kelly, J.N.D., 1995,Golden Mouth; The Story of John Chrsostom-Ascetic, Preacher, Bishop, New York: Cornell University Press.

Kristiyanto, Eddy, 2007, Selilit Sang Nabi; Bisik-Bisik tentang Aliran Sesat,Yogyakarta: Kanisius.

LaVerdiere, E.,1996, The Eucharist in the New Testament and the Early Church, Minnesota:The Liturgical Press.

Louw, J.P. and E.A. Nida, 1988, Greek-English Lexicon of the New Testament; Based on Semantic Domains, Vol. I-II, New York:United Bibles Societies.

Martasudjita, E.,2005, Ekaristi: Tinjauan Teologis, Liturgis, dan Pastoral,Yogyakarta: Kanisius.

McGinn, Bernard,1999, The Doctors of The Church; Thirty-Three Men and Women who Shaped Christianity, New York: The Crossroad Publishing Company.

Menken, M.J.J., 1997, “John 6:51c-58: Eucharist or Christology?”, in Critical Reading of John 6, edited by R. Alan Culpepper, Leiden-New YorkKöln:Brill.

Migne, J.-P., Patrologiae Cursus Completus, 1859, Patrologiae Graecae Tomus LIX: S. Joannes Chrysostomus, Montrouge:Bibliothecae Cleri Universae.

Moloney, F.J.,1998, The Gospel of John, Sacra Pagina Series, Vol 4, Minnesota:The Liturgical Press, Collegeville.

Neuner-J. Dupuis, J., 1996, Christian Faith in the Doctrinal Documents of The Catholic Church, Bangalore, India: Theological Publications.

Pius XII, Divino Afflante Spiritu (30 September 1943), diakses dari http://www.vatican.va/holy_father/pius_xii/ency clicals/documents/hf_pxii_enc_19430930_divino-afflantespiritu_lt.html, (18 Januari 2013).

Quasten, J., 1960, Patrology, Vol. III, Maryland:The Newman Press.

Williams, R, 2001, .Arius; Heresy and Tradition,Michigan: Wiliam B. Eerdmans Publishing Company. 